\title{
Review of the use of nasal and oral antiseptics during a global pandemic
}

\author{
Christopher Stathis $^{1}$ (D), Nikolas Victoria1 ${ }^{1 D}$, Kristin Loomis ${ }^{1}$, Shaun A Nguyen ${ }^{2}$, Maren \\ Eggers $^{3}$, Edward Septimus ${ }^{4} \&$ Nasia Safdar*,5 \\ ${ }^{1}$ HHV-6 Foundation, Santa Barbara, CA 93108, USA \\ ${ }^{2}$ Department of Otolaryngology, Head \& Neck Surgery, Medical University of South Carolina, Charleston, SC 29425, USA \\ ${ }^{3}$ Prof Dr G Enders MVZ Laboratory \& Institute of Virology, Infectious Diseases, Stuttgart, BW 70193, Germany \\ ${ }^{4}$ Department of Population Medicine, Harvard Medical School \& the Harvard Pilgrim Healthcare Institute, Boston, MA 02215, USA \\ ${ }^{5}$ Division of Infectious Disease, Department of Medicine, University of Wisconsin School of Medicine \& Public Health, Madison, WI, \\ USA \& The William S Middleton Memorial Veterans Hospital, Madison, WI 53726, USA \\ *Author for correspondence: Tel.: 608213 4075; ns2@medicine.wisc.edu
}

\begin{abstract}
A review of nasal sprays and gargles with antiviral properties suggests that a number of commonly used antiseptics including povidone-iodine, Listerine ${ }^{\circledR}$, iota-carrageenan and chlorhexidine should be studied in clinical trials to mitigate both the progression and transmission of SARS-CoV-2. Several of these antiseptics have demonstrated the ability to cut the viral load of SARS-CoV-2 by $3-4 \log _{10}$ in $15-30 \mathrm{~s}$ in vitro. In addition, hypertonic saline targets viral replication by increasing hypochlorous acid inside the cell. A number of clinical trials are in process to study these interventions both for prevention of transmission, prophylaxis after exposure, and to diminish progression by reduction of viral load in the early stages of infection.
\end{abstract}

Tweetable abstract: Commonly used antiseptics including povidone-iodine, Listerine ${ }^{\circledR}$, iotacarrageenan and chlorhexidine should be studied in clinical trials to mitigate the progression and transmission of SARS-CoV-2.

First draft submitted: 16 November 2020; Accepted for publication: 16 December 2020; Published online: 19 January 2021

Keywords: chlorhexidine $\bullet$ COVID-19 $\bullet$ hydrogen peroxide $\bullet$ hypertonic saline $\bullet$ iota-carrageenan $\bullet$ nasal spray $\bullet$ oral rinse $\bullet$ povidone-iodine $\bullet$ respiratory infections $\bullet$ SARS-CoV-2

The nose is both a source of pathogens and a critical port of entry for infectious agents such as viruses and bacteria. Proper hand hygiene is an essential step in infection prevention and control, but the nose and throat, critical portals of entry for infectious germs, are often not addressed. In terms of the current pandemic, some evidence indicates that viral titers of SARS-CoV-2 are extremely high in the nose and throat [1]. The hACE2 receptor, used by SARS-CoV-2 to establish infection, is found to be highly expressed in the mucosa of the oral cavity and nasal tissues [2].

Many preparations of antiseptics such as povidone-iodine (PVP-I), alcohol with essential oils, chlorhexidine (CHX), hydrogen peroxide (HP) and iota-carrageenan (IC) are widely used and safe for application to the epithelium. Hypertonic saline has also been investigated as an intervention against respiratory infections. WHO Interim guidance for dental practices recommends asking patients to rinse their mouths with $1 \%$ hydrogen peroxide or $0.2 \%$ PVP-I for $20 \mathrm{~s}$ prior to examination or starting any procedure for the purpose of reducing the salivary load of oral microbes, including SARS-CoV-2 [3].

This review explores common and/or promising antiseptic techniques and some of the ongoing clinical trials that are investigating the use of these antiseptic compounds as potential treatments and preventative measures.

\section{Materials \& methods}

A preliminary search for this review was conducted in PubMed using the search terms 'nasal antisepsis' and 'throat antisepsis' paired independently with 'antiviral' and 'virus'. Based on the result of that initial search, an additional 
search was performed pairing the terms 'povidone-iodine gargle', 'betadine gargle', 'hypertonic saline gargle', 'Nozin', 'chlorhexidine gargle', 'hydrogen-peroxide gargle', 'dequonal', 'dequalinium chloride' and 'benzalkonium chloride' independently with 'antiviral' and 'virus'. Articles from these searches, as well as articles referenced within the resulting articles, were used to identify key search terms for a more systematic search.

Based on the preliminary search, a new search was conducted in PubMed using the following search terms: (SARS-CoV-2 OR Covid-19 OR coronavirus OR SARS-CoV OR middle east respiratory syndrome coronavirus (MERS-CoV) OR SARS OR MERS) AND (nasal OR throat OR oral) AND (antimicrobial OR mouthwash OR rinse OR gargle OR antisepsis OR antiviral OR virucide OR biocide OR antiseptic prophylaxis) AND (catechin OR cyclodextrin OR citrox OR quaternary ammonium compounds OR cetrimide OR octenidine dihydrochloride OR dequonal OR benzalkonium chloride OR dequalinium chloride OR sage extract OR sodium hypochlorite OR PVP OR Nozin OR chlorhexidine OR cetylpyridinium chloride OR ethanol OR hydrogen peroxide OR hypertonic saline OR carrageenan). This search resulted in 47 individual results. The resulting studies were then fully read by two co-authors and additional papers were added after reference mining. Compounds were excluded if they were not commercially available. The only class of compounds that were commercially available but were excluded were the quaternary ammonium compounds due to safety concerns identified during the preliminary search.

A final search was performed of the clinicaltrials.gov database using the search terms (nasal spray OR gargle) AND SARS-CoV-2 to identify relevant clinical trials. A total of 20 unique results were identified, and trials were excluded based on the following criteria: non-randomized controlled trials, trials with fewer than 20 participants.

\section{Results \\ PVP-I (betadine)}

PVP-I is one of the most common antiseptics available and is considered safe to use on the mucosal epithelium at appropriate concentrations [4]. For the skin, PVP-I typically comes in a 10\% preparation as well as a $1 \%$ preparation for the oral cavity, and is available in many countries including Japan, Australia and Canada [5]. Eggers et al. reported at a $0.23 \%$ dilution of $7 \%$ PVP-I mouthwash reduced viral titers of two coronaviruses similar to SARS-CoV-2, SARS-CoV and MERS-CoV, by over $4 \log _{10}$ after a $15 \mathrm{~s}$ exposure in vitro [6]. A list of the compounds and their effects on SARS-CoV-2 in vitro can be found in Table 1, and their effects on viruses other than SARS-CoV-2 can be found in Supplementary Table 1. In a clinical setting, gargling with PVP-I solution resulted in a 50\% drop in respiratory infections caused by pathogens such as Pseudomonas aeruginosa, Staphylococcus aureus and Haemophilus influenzae [7]. Against SARS-CoV-2, in vitro testing of PVP-I at concentrations ranging from 10.0 to $0.45 \%$ were reported to yield a greater than $4.00 \log _{10}$ reduction in viral titers after only a $30 \mathrm{~s}$ exposure [8]. PVP-I was also shown to have rapid inactivation of SARS-CoV-2 in vitro at concentrations of $1.5-0.5 \%$ after a $15 \mathrm{~s}$ exposure time with a $3.0 \log _{10}$ reduction in viral titers [9]. In a preprint, in vivo toxicity study of PVP-I revealed no toxicity concerns with sub-chronic intranasal use of PVP-I [10]. PVP-I may be tolerable as not only an oral mouthwash but also as a nasal spray [11]. In one in vivo study of the effects of PVP-I on SARS-CoV-2 viral load, there was a decrease in viral load for two out of four patients after a $15 \mathrm{ml}$ oral rinse of 1.0\% PVP-I for $1 \mathrm{~min}$ [12]. A clinical study in 2007 showed PVP-I nasal spray at concentrations of 4.4 and 2.2\% have shown no damage to the epithelium of the nasopharynx [5]. 3M has developed a PVP-I nasal swab for decolonization that includes a film forming polymer that increases persistence to $12 \mathrm{~h}$ [13]. Nasal PVP-I solution was more tolerable than traditional mupirocin nasal wash as a method of reducing $S$. aureus prior to surgery [14]. No true allergy to PVP-I has been noted, but a small percentage may develop low level skin irritation [15].

Several clinical trials are underway that compare PVP-I at different concentrations and other antiseptics. In one of these studies, PVP-I $0.20 \%$ will be used as a gargle and nasal lavage for 20-30 s three times a day for 6 days [20]. This trial will also compare PVP-I to hydrogen peroxide, neem extract (an herbal antimicrobial) and hypertonic saline to elucidate which (if any) treatment reduces intraoral viral load. This safety of PVP-I as a gargle or nasal spray is assumed and will not be evaluated.

There is some evidence that betadine, a commercially available form of PVP-I, may decrease mucociliary clearance at a concentration of $5-10 \%$ by inhibiting ciliary beating of nasal epithelial cells in the sinonasal mucosa, indicating possible cilial toxicity [21]. However, there have been other papers with betadine products that demonstrate that there is no ciliotoxicity of PVP-I products [5,22]. 
Table 1. In vitro effects of commercial nasal and oral rinses against SARS-CoV-2.

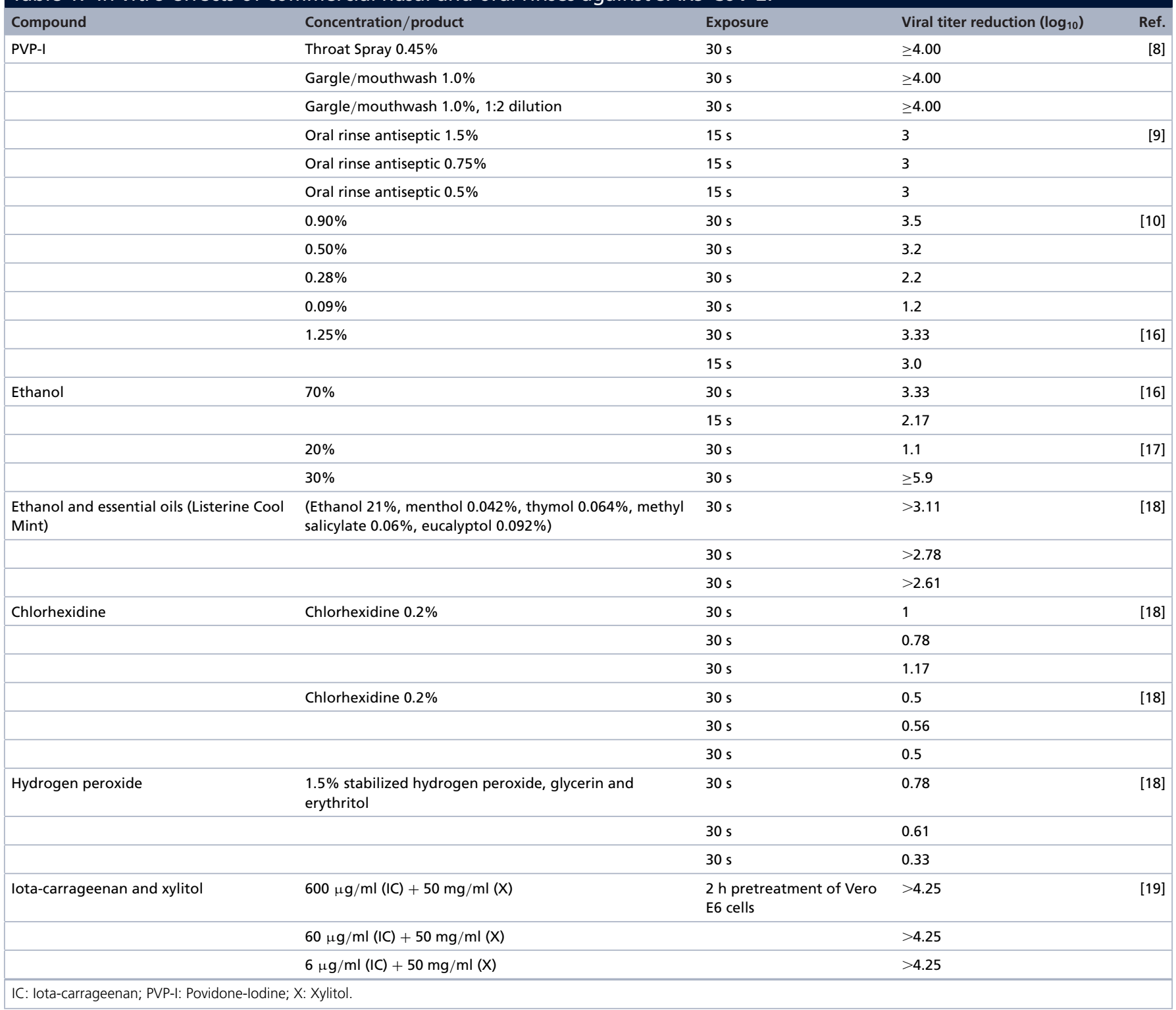

There is also concern that PVP-I may have unknown effects on the microbial flora of the oral cavity [23]. PVP-I showed no deleterious effect on a representative nitrate-reducing species called Veillonella dispar in the oral cavity suggesting it may not have an effect on the normal oral microbial flora [24].

\section{lota-carrageenan}

Iota-carrageenan is a sulphated polysaccharide purified from red marine algae and has been shown to inhibit rhinovirus, influenza A and multiple herpesviruses in vitro [25,26]. In one preprint study, iota-CARRAGEENAN with xylitol inhibited SARS-CoV-2 by a reduction factor of $>4.25 \log _{10}$ in vitro at iota-carrageenan concentrations of 600,60 and $6 \mu \mathrm{g} / \mathrm{ml}$, with a xylitol concentration of $50 \mathrm{mg} / \mathrm{ml}$ [19]. In a randomized controlled trial, iotacarrageenan nasal spray was tolerable in patients with the common cold and had a good safety profile [27]. Xylitol itself has also demonstrated antiviral properties [28]. 


\section{Hypertonic saline}

Several studies support the use of hypertonic saline as a preventative measure against respiratory viruses and there are already commercially available hypertonic saline rinses in many countries. Nasal saline rinses are well tolerated and there is evidence that they decrease the severity of upper respiratory tract infections [29].

Several randomized controlled trials have shown the efficacy of salt water in acute upper respiratory tract infections [30]. A small randomized controlled trial in the UK reported that saline irrigation and gargling reduced the duration of viral upper respiratory tract infections by 1.9 days $(\mathrm{p}=0.01)$, reduced the transmission to household contacts by $35 \%(\mathrm{p}=0.006)$, reduced the use of over the counter medications by $36 \%(\mathrm{p}=0.004)$. More individuals in the intervention arm reduced viral shedding by $>0.5 \log _{10} /$ day compared with controls $(\mathrm{p}=0.04)$ [31]. The mechanism for the efficacy of saline against various viruses in the upper respiratory tract is that increased availability of local chloride ions (from $\mathrm{NaCl}$ ) supports the production of hypochlorous acid (the active ingredient in bleach), a potential innate immune mechanism in epithelial cells [30,32]. The addition of $\mathrm{NaCl}$ to the cell culture medium inhibited various human viruses in a dose-dependent manner. Human coronavirus $229 \mathrm{E}$ replication was inhibited by saline concentrations between 30 and $50 \mathrm{mM}$ [32]. Importantly, the entry of $\mathrm{Cl}^{-}$ion into the cells and its conversion by a peroxidase to hypochlorous acid was found to be necessary for the observed antiviral activity [32]. The data did not support any other mechanism (i.e., virucidal, adsorption inhibition). A study investigating the effect of hypertonic saline on SARS-CoV-2 in vitro, available on the preprint server, showed that $210 \mathrm{mM} \mathrm{NaCl}$ $(1.2 \%)$ inhibited virus replication by $90 \%(\mathrm{p}<0.0005)$ and $260 \mathrm{mM} \mathrm{NaCl}(1.5 \%)$ inhibited viral replication by $100 \%$ ( $\mathrm{p}<0.0005)$ in Vero CCL-81 cells when compared with $110 \mathrm{mM} \mathrm{NaCl}(0.6 \%)$ [33]. The concentration of $\mathrm{NaCl}$ in the mucus layer found in the respiratory tract measured by in vivo tests has been reported to be in a range of $110 \mathrm{mM}(0.6 \%)-130 \mathrm{mM}(0.76 \%)$ [34,35]. Any $\mathrm{NaCl}$ solution with a concentration $>130 \mathrm{mM}$ that is applied to the nasopharynx would result in a net increase in chloride ions and sodium ions in the mucus layer.

\section{Alcohol \& essential oils}

In one German in vitro study, 30 s of exposure to $78 \%$ alcohol reduced SARS viral loads by $\geq 5 \log _{10}$, effectively inactivating the virus [36]. In another in vitro study investigating WHO-recommended formulations of virucidal agents, 30 s of exposure to $20 \%$ ethanol reduced SARS-CoV-2 infectivity by $1.1 \log _{10}$ and a $30 \mathrm{~s}$ exposure to $30 \%$ ethanol reduced infectivity by $\geq 5.9 \log _{10}$ [17]. The active compounds of Listerine ${ }^{\circledR}$, a widely used oral rinse, that includes ethanol as an inactive ingredient with essential oils; eucalyptol, menthol, methyl salicylate and thymol has been found to significantly reduce virus activity [18]. In addition to ethanol, the essential oils each have independent antimicrobial and anti-inflammatory properties [37]. In quantitative suspension studies, conducted by researchers in Germany, several SARS-CoV-2 strains showed log reduction factors of 2.61-3.11 after being incubated in the Listerine Cool Mint formulation (21\% ethanol) for $30 \mathrm{~s}$ [18].

Nozin Nasal Sanitizer is an ethanol-based nasal antiseptic commonly used in hospitals and surgical units that is reported to reduce median $S$. aureus units by $99 \%$ [38]. The product consists of $60-70 \%$ ethanol with jojoba and vitamin $\mathrm{E}$ to moisturize the nose, and it is applied around the inside of the vestibular surface of the nostrils using a sterile swab.

A Listerine product consisting of eucalyptol $0.092 \%$, menthol $0.042 \%$, methyl salicylate $0.060 \%$ and thymol $0.064 \%$, in $25 \%$ ethanol has been reported to have no detrimental effect to the representative nitrate-reducing bacteria $V$. dispar of the mouth [24]. No toxicity, or deleterious effects on the oral microbiota have been reported for occasional use.

\section{Chlorhexidine}

CHX mouthwash, widely used for gum disease, demonstrates bactericidal and virucidal activity against enveloped viruses such as coronaviruses $[6,39,40]$. The bactericidal activity is caused by the nonspecific binding of the positively charged chlorhexidine molecule to the membrane phospholipids of bacteria [41]. Some evidence indicates CHX is less effective in rapid elimination of human coronaviruses compared with other virucidal agents such as alcohols and PVP-I [42], but it also binds to proteins on the skin which expands the duration of protection up to $24 \mathrm{~h}$ [43]. One study in South Korea reported in two patients, there was a decrease in SARS-CoV-2 viral load for $2 \mathrm{~h}$ following the use of $15 \mathrm{ml}$ of $0.12 \%$ chlorhexidine gluconate (CHG) mouthwash based on real-time PCR [44]. Chlorhexidine has been reported to be safe in the nasopharynx as a gel but there has not been much study of chlorhexidine as a nasal spray [45]. 


\begin{tabular}{|c|c|c|c|c|c|c|}
\hline Clinical trial \# & Compounds tested & Use & EST (n) & Country & Start date & Ref. \\
\hline NCT04371965 & PVP-I & Gargle or nasal spray & 24 & France & Q3 20 & [49] \\
\hline NCT04341688 & PVP-I, HP, neem extract and HS & Nasal lavage and gargle & 50 & Pakistan & Q3 20 & [20] \\
\hline NCT04347954 & PVP-I or isotonic saline & Nasal spray & 45 & USA & Q3 20 & [50] \\
\hline NCT04410159 & PVP-I, Listerine or tap water & Gargle & 20 & Malaysia & Q3 20 & [51] \\
\hline NCT04521322 & IC & Nasal spray & 400 & Argentina & Q3 20 & [52] \\
\hline NCT04364802 & PVP-I & Nasal spray and gargle & 250 & USA & Q2 20 & [53] \\
\hline NCT04352959 & Beta-cyclodextrin and citrox & Gargle & 206 & France & Q2 20 & [54] \\
\hline NCT04449965 & PVP-I & Nasal rinse and gargle & 81 & Canada & Q3 20 & [55] \\
\hline NCT04344236 & Saline, PVP-I or CHX & Nasal rinse and gargle & 48 & USA & Q2 20 & [56] \\
\hline NCT04409873 & $\begin{array}{l}\text { Distilled water, HP, CPC, chlorine dioxide or } \\
\text { Listerine (zero alcohol) }\end{array}$ & Gargle & 150 & USA & Q4 20 & [57] \\
\hline NCT04478019 & PVP-I + CHG & PVP-I nasal swab $+\mathrm{CHX}$ gargle & 94 & USA & Q3 20 & [58] \\
\hline NCT04549376 & PVP-I & Nasal irrigation & 200 & Bangladesh & Q3 20 & [59] \\
\hline NCT04393792 & PVP-I or normal saline & Nasal rinse and gargle & 40 & UK & Q2 20 & [60] \\
\hline NCT04563689 & CHG or CPC & Gargle & 24 & Colombia & Q2 20 & [61] \\
\hline NCT04337918 & NORS & Nasal spray and gargle & 200 & Canada & Q2 20 & [62] \\
\hline NCT04537962 & $\mathrm{CHX}, \mathrm{HP}, \mathrm{CPC}$, zinc lactate & Mouthwash & 70 & Brazil & Q2 20 & [63] \\
\hline NCT04443868 & NORS or saline & Nasal spray and nasal irrigation & 300 & Canada & Q3 20 & [64] \\
\hline
\end{tabular}

\section{Hydrogen peroxide}

A $0.5 \%$ solution of accelerated hydrogen peroxide was able to reduce infectivity of human coronavirus $229 \mathrm{E}$ by greater than $4 \log _{10}$ after $60 \mathrm{~s}$ exposure in suspension tests [46]. Accelerated hydrogen peroxide also contains other ingredients such as surfactants that may contribute to its effectiveness so it is not clear that hydrogen peroxide alone was effective. A randomized trial of 68 intensive care unit patients reported that those whose oral cavities were washed with $3 \%$ hydrogen peroxide were significantly less likely to develop ventilator-associated pneumonia compared with controls who gargled saline [47]. Washes were performed by hospital staff using cotton swabs soaked in $15 \mathrm{cc}$ of $3 \%$ hydrogen peroxide. Hydrogen peroxide mouthwash in one study reduced viral titers in three separate strains of SARS-CoV-2 but the reduction was not significant [18]. In one clinical pilot study of ten SARS-CoV-2 positive patients hydrogen peroxide $1 \%$ was not shown to reduce intraoral viral load [48].

\section{Clinical trials}

Currently, there are over 20 trials testing the efficacy and tolerability of PVP-I, Listerine, iota-carrageenen, hypertonic saline, chlorhexidine, baby shampoo and hydrogen peroxide (see Table 2). We found 17 clinical trials that met our criteria. There is currently a systematic review being done by the Cochrane review of clinical trials for SARS-CoV2 [23].

One clinical trial that has been completed at the Universiti Sains Islam Malaysia and has results for 20 participants is investigating the use of a PVP-I gargle or Listerine gargle on early viral clearance of SARS-CoV-2 defined as two negative real-time PCR results at least $24 \mathrm{~h}$ apart [51]. One clinical trial is investigating the efficacy of iotacarrageenan nasal spray use four times per day for 21 days as a preventative measure in healthcare workers [52]. The SHIELD study in the USA at the University of Wisconsin, Madison, is investigating the preventative efficacy against SARS-CoV-2 of a combination of PVP-I nasal swabs and chlorhexidine oral rinse [58]. A pilot study sponsored by Colgate Palmolive and Hospital Israelita Albert Einstein are investigating different formulations of Colgate ${ }^{\circledR}$ Peroxyl ${ }^{\circledR}$ hydrogen peroxide mouthwash and Colgate Periogard ${ }^{\circledR}$ chlorhexidine oral rinse to determine effect on SARS-CoV-2 viral load [63].

NYU Langone is sponsoring a clinical trial that compares saline oral/nasal rinse to PVP-I and CHX in patients with a positive COVID-19 test [56]. For each potential treatment, participants will do a $5 \mathrm{cc}$ nasal rinse in each nostril followed by a $20 \mathrm{cc}$ oral gargle four times per day for 7 days. The viral load of SARS-CoV-2 will be measured by using cycle time to PCR as a proxy for viral load. 
Vanderbilt University Medical Center is conducting a clinical trial of two interventions, saline nasal irrigation twice daily and normal saline with $1 / 2$ teaspoon of baby shampoo nasal irrigation twice daily [65]. The primary outcomes measured will be change in SARS-CoV-2 mucosal immune response measured using viral RNA, change in microbial load in the nasopharynx and viral load in the nasopharynx based on quantitative PCR [65]. Based on the interim analysis of this study, nasal congestion and headache symptoms resolved 7-9 days earlier in the intervention groups compared with the no intervention group [66].

The University of Edinburgh is also conducting a clinical trial investigating the efficacy of hypertonic saline in patients with clinically suspected or confirmed COVID-19 [67]. The primary outcome of the study is time to resolution of symptoms.

Stanford HealthCare is conducting a clinical trial investigating PVP-I nasal sprays compared with normal saline nasal sprays [50]. In the trial patients with a COVID-19 diagnosis and a positive lab test will receive either 2, $0.5 \%$ PVP-I or isotonic saline $0.9 \%$ nasal spray as two sprays in each nare from a nasal spray bottle, four times per day. Change in viral titers of SARS-CoV-2 will be measured by quantitative PCR [50].

\section{Discussion}

The rapid expansion of the COVID-19 pandemic has increased interest in finding safe and effective options for protecting healthcare workers and those at greatest risk of exposure.

PVP-I nasal spray and mouthwash could be considered a safe and potentially effective option against SARS$\mathrm{CoV}-2$ based on preliminary in vitro and in vivo studies cited in this review, although rigorous clinical trial data on SARS-CoV-2 are awaited to better understand the magnitude of effect and efficacy $[16,68,69]$.

Tolerable commercial products containing saline that are used in nasal irrigation and as nasal sprays typically are at $\mathrm{NaCl}$ concentrations considered to be isotonic at $0.9 \%$ and hypertonic (up to 3.0\%) [70]. The concentrations of $\mathrm{NaCl}$ mentioned in this review that have been investigated in vitro against SARS-CoV-2 and HCoV-229E range from $30 \mathrm{mM}(0.17 \% \mathrm{NaCl})$ to $260 \mathrm{mM}(1.5 \% \mathrm{NaCl})$. After irrigation with saline, most of the liquid will run out of the nose or mouth, removing excess mucous and leaving a thin film of salty water. The cells will then absorb chloride ion, so the concentration will change over time, and once the $\mathrm{HOCl}$ is used up, the virus will start to replicate again. Any $\mathrm{NaCl}$ concentration greater than $130 \mathrm{mM}$ would result in a net increase in chloride ions adjacent to the nasal epithelium. A concentration of $260 \mathrm{mM} \mathrm{NaCl}(1.5 \%)$ shows the greatest inhibition of viral replication. Concentrations above $260 \mathrm{mM} \mathrm{NaCl}$ would be expected to suppress viral replication for a longer period of time. The increased chloride ion concentration in these cavities would cause the epithelial cells (where the virus replicates) to take up chloride, increasing the hypochlorous acid concentration through the activity of a peroxidase. This innate immune mechanism in epithelial cells may halt viral replication [32]. Additionally, increasing the $\mathrm{NaCl}$ concentration outside of the cells may result in the movement of water by osmosis out of the cells into the oral and nasal cavities which would have an added benefit of loosening mucous secretions and potentially easing some of the symptoms caused by SARS-CoV-2.

Listerine is a combination of up to $25 \%$ ethanol (at varying concentrations) plus essential oils that are both soothing and antimicrobial including eucalyptol, menthol, thymol and methyl salicylate [24]. The original Cool Mint Listerine has been reported to be similarly effective against SARS-CoV-2 in vitro as PVP-I [18]. In one preprint study, ethanol alone without essential oils at the concentrations found in Listerine at 21 and $23 \%$ in vitro, showed no virucidal activity indicating that the essential oils included are required for the virucidal activity observed [71]. This is consistent with data from one study that showed $20 \%$ ethanol decreased viral titers in vitro by $1.1 \log _{10}$, but increasing the ethanol concentration to $\geq 30 \%$ coincided with a decrease in viral titers by $\geq 5.9 \log _{10}[17]$. Another alcohol-based antiseptic, Nozin, has primarily been studied for decolonization of the nose to prevent Staphylococcus infections (MRSA, methicillin-susceptible Staphylococcus aureus), and while 60-70\% is within the CDC-recommended alcohol content to kill most pathogens including viruses, no studies have investigated the efficacy of Nozin against specific viral infections [38]. It should also be noted that as an alcohol-based sanitizer, the duration of activity of Nozin is relatively short, and thus may need to be administered frequently for maximum effectiveness. Further study is warranted for alcohol and essential oil-based antiseptics against SARS-CoV-2.

Chlorhexidine is being evaluated in current clinical trials given its use as an oral mouthwash, its history as an antiseptic in surgery, and data supporting its possible effectiveness against SARS-CoV-2 [44,45,56]. In the study conducted in South Korea, there were only two patients and the viral load increased following the $2 \mathrm{~h}$ period of improvement [44]. This study was not placebo controlled so it is not clear whether chlorhexidine has a direct antiviral effect in vivo or if the reduction is just due to washing away viral particles without halting viral replication. This 


\begin{tabular}{|c|c|c|c|c|c|c|c|c|}
\hline Clinical trial \#/intervention & Use & Conc. & $\begin{array}{l}\text { Intervention } \\
\text { (n) }\end{array}$ & Placebo (n) & $\mathrm{TSS}_{(2-4)}$ & $\begin{array}{l}\text { Reduction in } \\
\text { duration of illness } \\
\text { vs control }\end{array}$ & p-value & Ref. \\
\hline $\begin{array}{l}\text { NCT02438579/hypertonic } \\
\text { saline nasal irrigation and } \\
\text { gargling }\end{array}$ & $\begin{array}{l}\text { Six times per day for first } \\
2 \text { days, and reducing } \\
\text { frequency on day } 3 \text { as } \\
\text { symptoms improve }\end{array}$ & $1.5-3.0 \%$ & 30 & 31 & $\mathrm{~N} / \mathrm{A}$ & $\begin{array}{l}1.9 \text { days }(95 \% \\
\mathrm{Cl}=0.4-3.3)\end{array}$ & 0.01 & [78] \\
\hline $\begin{array}{l}\text { Eudract number } 2007- \\
007577-23 / \text { carrageenan } \\
\text { nasal spray }\end{array}$ & $\begin{array}{l}\text { One spray to each nostril } \\
\text { three times per day for } \\
4 \text { days }\end{array}$ & $\begin{array}{l}\text { Coldamaris nasal } \\
\text { spray }(0.12 \% \\
\text { Carrageenan }\end{array}$ & 14 & 18 & $\begin{array}{l}\text { Intervention: } \\
4.62 \pm 2.06 \\
\text { Placebo: } \\
6.28 \pm 2.29\end{array}$ & $\mathrm{~N} / \mathrm{A}$ & $<0.046$ & [27] \\
\hline $\begin{array}{l}\text { ISRCTN52519535/carrageenan } \\
\text { nasal spray }\end{array}$ & $\begin{array}{l}\text { Three times per day for } \\
7 \text { days }\end{array}$ & $\begin{array}{l}\text { Coldamaris nasal } \\
\text { spray }(0.12 \% \\
\text { carrageenan })\end{array}$ & 77 & 77 & $\mathrm{~N} / \mathrm{A}$ & 1.8 days & $<0.038$ & {$[77,80]$} \\
\hline $\begin{array}{l}\text { ISRCTN80148028/carrageenan } \\
\text { nasal spray }\end{array}$ & $\begin{array}{l}\text { Three times per day for } \\
7 \text { days }\end{array}$ & $\begin{array}{l}\text { Coldamaris nasal } \\
\text { spray }(0.12 \% \\
\text { carrageenan })\end{array}$ & 51 & 52 & $\mathrm{~N} / \mathrm{A}$ & 2.1 days & 0.037 & {$[77,81]$} \\
\hline $\begin{array}{l}\text { NCT01944631/carrageenan } \\
\text { nasal spray }{ }^{\dagger}\end{array}$ & $\begin{array}{l}\text { One puff into each } \\
\text { nostril four times per day } \\
\text { for } 4-10 \text { days }\end{array}$ & $\begin{array}{l}1.20 \mathrm{~g} / \mathrm{l} \\
\text { iota-carrageenan }\end{array}$ & 97 & 97 & $\begin{array}{l}\text { Intervention: } \\
5.67 \\
\text { placebo: } 6.39\end{array}$ & $\mathrm{~N} / \mathrm{A}$ & 0.0364 & {$[76,79]$} \\
\hline
\end{tabular}

provides some support that Chlorhexidine could be a useful oral antiseptic against SARS-CoV-2 in the short term, but there needs to be a larger randomized placebo-controlled trial to elucidate whether chlorhexidine is suitable for widespread use. There are also several safety concerns such as concentration-dependent skin irritation, potential conjunctivitis, potential corneal damage if exposed to the eye, teeth staining and potential ototoxicity [72,73]. Chlorhexidine has also been reported to have a detrimental effect on a representative nitrate-reducing bacteria $V$. dispar of the oral microbiome indicating consistent use at high doses could have a negative effect on the flora of the oral cavity over time [24]. Given these concerns, chlorhexidine may be best used at a low concentration of $0.12 \%$, such as those being evaluated in ongoing clinical trials.

Hydrogen peroxide has been used as an oral rinse for patients on ventilators to prevent ventilator-related pneumonia [47]. However, the in vitro data available for hydrogen peroxide suggests, it is less effective than PVP-I and Listerine in reducing the viral load of SARS-CoV-2 in the oral cavity [18]. One small study of hydrogen peroxide in ten patients reported no significant reduction of intraoral viral load in SARS-CoV-2 positive patients [48]. Hydrogen peroxide has been considered safe to use as a tooth-whitening treatment, but may cause tooth sensitivity and gingival irritation which is concentration dependent [74]. More research on the potential safety concerns of hydrogen peroxide may be required before it should be used as a widespread oral antiseptic. There are currently several clinical trials investigating some commercial hydrogen peroxide products that may be able to provide more information on the efficacy and safety of hydrogen peroxide as a means of preventing SARS-CoV-2 transmission [63].

Iota-carrageenan is nontoxic and works by creating a physical barrier against viruses in a nonclinical study of the compound [75]. The compound has also been reported to be effective against the common cold compared with placebo in clinical trials, making it a good potential candidate for reducing transmission of SARS-CoV-2 [76]. In an analysis of two randomized controlled studies of iota-carrageenan against the common cold, iota-carrageenan was shown to be more effective than placebo at reducing the duration of symptoms in patients infected with human coronavirus by 3.9 days on average in one trial $(p<0.01)$ and 3.1 days in the other trial $(p<0.01)$ [77]. Iota-carrageenan has been reported to be effective against SARS-CoV-2 in vitro alone and in combination with xylitol [19]. There currently is no published in vivo data, but iota-carrageenan is being investigated in a clinical trial as a preventative measure against COVID-19 [52].

Hypertonic saline halts replication inside the cell by increasing hypochlorous acid, so direct comparison with antiseptics PVP-I, Listerine, iota-carrageenan and chlorhexidine that have a direct effect on free virus in vitro, can be misleading. To date, hypertonic saline and iota-carrageenan are the only interventions that have been shown to reduce the duration of symptoms of coronaviruses in randomized controlled trials investigating the common cold [30,78-81]. Details of these randomized controlled trials can be found in Table 3. There are different mechanisms employed by each of the interventions mentioned in this review. One potential benefit besides the antiviral activity 
of these interventions is the mechanical effect of washing viral particles away, and frequency of use may be an important factor for success. There may be an advantage to combining or alternating between antiseptic and saline nasal and oral rinses in order to enhance results.

Clinical trials of other antimicrobial compounds include neem extract, beta-cyclodextrins, nitric oxide-releasing solutions (NORS), baby shampoo and intranasal heparin. Neem extract is a solution created from the ethanol extraction of the Azadirachta indica plant that is composed of many organic compounds that are reported to have antimicrobial, antifungal and antiviral properties $[82,83]$. Beta-cyclodextrins, commonly used to improve delivery of hydrophobic compound, are reported to have some antiviral properties [84]. NORS treatment may be useful due to nitric oxide having immunoregulatory and antiviral properties [85]. Heparin has been proposed as a potential therapeutic nasal rinse against COVID-19 as a potential antiviral based on the strong affinity that the SARS-CoV-2 spike protein has for heparin [86]. There is some evidence that baby shampoo is effective against HCoV-229E and is currently being evaluated [87]. Baby shampoo is composed of surfactants and has been investigated as an adjunct therapy in chronic rhinosinusitis [88]. The amphiphilic property of surfactants suggests that baby shampoo may be useful against enveloped viruses such as coronaviruses. Randomized clinical trials of nitric oxide-releasing solution SaNOtize and intranasal heparin are currently underway.

Most of the compounds described in this review have already been in widespread use, so safety concerns are minimal. However, further evaluation of the safety of these compounds should be conducted, to rule out potential issues that might include alteration of oral flora in the mouth and nasal passages, tooth staining, irritation of the epithelia, as well as potential anosomia (loss of smell).

There is sufficient evidence to justify further evaluation of mouthwashes (chlorhexidine, Listerine, hypertonic saline, hydrogen peroxide, iota-carrageenan) and nasal treatments (Nozin, PVP-I, chlorhexidine, hypertonic saline and iota-carrageenan) for reducing the rate of transmission; mitigation of disease progression by reduction of viral load very early after infection; and prophylaxis after exposure to SARS-CoV-2.

\section{Conclusion}

While nasal sprays and gargles cannot replace the use of traditional personal protective equipment (i.e., gowns, masks, protective eyewear and gloves), the use of nasal and oral antisepsis has the potential to be useful for combating SARS-CoV-2. Clinical trials currently underway will be the best mechanism to determine the true benefit of these compounds and their role in mitigating disease progress and transmission of SARS-CoV-2 infection.

\section{Future perspective}

Several of the compounds in this review may be commonly used against not only SARS-CoV-2 but also many other viruses given their broad-spectrum antimicrobial effects. The results of ongoing and future clinical trials will determine the role of these agents for SARS-CoV-2 mitigation. Given that these agents are broad-spectrum antiseptics rather than antibiotics, the risk of resistance over time may be low but should also be studied.

\section{Executive summary}

\section{Methods}

- A review of literature was conducted regarding the use of commercially available antiseptics and SARS-CoV-2.

Results

- Povidone-iodine (betadine), ethanol and essential oils (Listerine) and a combination of xylitol and iota-carrageenan (purified from red marine algae) were shown to reduce viral load of SARS-CoV-2 in vitro by 3-4 $\log _{10}$ in $30 \mathrm{~s}$.

- Chlorhexidine, a widely used oral rinse, does not act as quickly in reducing viral load in $30 \mathrm{~s}$ as povidone-iodinel, but binds to cell proteins, extending protection.

- Hydrogen peroxide is not as effective as other oral rinses in vitro and cell toxicity is a concern.

- Hypertonic saline is not directly virucidal, but halts replication by increasing hypochlorous acid inside the cell.

Conclusion

- Several commonly used nasal antiseptics and gargles have shown efficacy against SARS-CoV-2 in vitro and clinical trials are currently underway to study their impact on disease course and transmission.

Future perspective

- These commercially available products should be further evaluated due to their potential ability to reduce the transmission of SARS-CoV-2 and other viruses that are yet to emerge. 


\section{Author contributions}

K Loomis, N Victoria and C Stathis were responsible for the initial literature acquisition and drafting of this work. K Loomis, N Safdar, $\mathrm{S}$ Nguyen, M Eggers and E Septimus assisted with data interpretation, subsequent literature acquisition and critical revisions. $\mathrm{K}$ Loomis was responsible for the original conception and design of this work.

\section{Financial \& competing interests disclosure}

N Safdar has received grant funding from PDI healthcare for a separate research project. The authors have no other relevant affiliations or financial involvement with any organization or entity with a financial interest in or financial conflict with the subject matter or materials discussed in the manuscript apart from those disclosed.

No writing assistance was utilized in the production of this manuscript.

\section{References}

Papers of special note have been highlighted as: • of interest; $\bullet \bullet$ of considerable interest

1. Zou L, Ruan F, Huang M et al. SARS-CoV-2 viral load in upper respiratory specimens of infected patients. N. Engl. J. Med. 382(12), 1177-1179 (2020).

2. Hamming I, Timens W, Bulthuis ML, Lely AT, Navis G, Van Goor H. Tissue distribution of ACE2 protein, the functional receptor for SARS coronavirus. A first step in understanding SARS pathogenesis. J. Pathol. 203(2), 631-637 (2004).

3. World Health Organization. Considerations for the provision of essential oral health services in the context of COVID-19: interim guidance (2020). https://apps.who.int/iris/handle/10665/333625

4. Nair B. Final report on the safety assessment of polyvinylpyrrolidone (PVP). Int. J. Toxicol. 17(Suppl. 4), 95-130 (1998).

5. Gluck U, Martin U, Bosse B, Reimer K, Mueller S. A clinical study on the tolerability of a liposomal povidone-iodine nasal spray: implications for further development. ORL J. Otorhinolaryngol. Relat. Spec. 69(2), 92-99 (2007).

6. Eggers M, Koburger-Janssen T, Eickmann M, Zorn J. In vitro bactericidal and virucidal efficacy of povidone-iodine gargle/mouthwash against respiratory and oral tract pathogens. Infect. Dis. Ther. 7(2), 249-259 (2018).

7. Nagatake T, Ahmed K, Oishi K. Prevention of respiratory infections by povidone-iodine gargle. Dermatology 204(Suppl. 1), 32-36 (2002).

8. Anderson DE, Sivalingam V, Kang AEZ et al. Povidone-iodine demonstrates rapid in vitro virucidal activity against SARS-CoV-2, the virus causing COVID-19 disease. Infect. Dis. Ther. 9(3), 669-675 (2020).

- Demonstrates a rapid decrease in viral titers of SARS-CoV-2 after the virus was exposed to varying concentrations of PVP-I.

9. Bidra AS, Pelletier JS, Westover JB, Frank S, Brown SM, Tessema B. Rapid in-vitro inactivation of severe acute respiratory syndrome coronavirus 2 (SARS-CoV-2) using povidone-iodine oral antiseptic rinse. J. Prosthodont. 29(6), 529-533 (2020).

- Demonstrates rapid in vitro inactivation of SARS-CoV-2 when exposed to PVP-I.

10. Liang B, Yuan X, Wei G et al. In-vivo toxicity studies and in-vitro inactivation of SARS-CoV-2 by povidone-iodine in-situ gel forming formulations. bioRxiv doi:10.1101/2020.05.18.103184 (2020) (Epub ahead of print).

-. This in vivo toxicity study demonstrates the safety of a PVP-I gel formulation and supports its potential use in preventing the transmission of SARS-CoV-2.

11. Khan MM, Parab SR, Paranjape M. Repurposing 0.5\% povidone iodine solution in otorhinolaryngology practice in Covid 19 pandemic. Am. J. Otolaryngol. 41(5), 102618-102618 (2020).

12. Martínez Lamas L, Diz Dios P, Pérez Rodríguez MT et al. Is povidone iodine mouthwash effective against SARS-CoV-2? First in vivo tests. Oral Dis. doi:10.1111/odi.13526 (2020) (Epub ahead of print).

13. 3M Health Care. Supporting antibiotic stewardship through effective nasal decolonization. https: $/ /$ multimedia. $3 \mathrm{~m} . c 0 m / \mathrm{mws} / \mathrm{media} / 17$ 29936O/3m-skin-and-nasal-antiseptic.pdf?elqTrackId=eab6a887bb8e4ee6844a84c842330d1 c\&elqaid=14627\&elqat=2

14. Lepelletier D, Maillard JY, Pozzetto B, Simon A. Povidone iodine: properties, mechanisms of action, and role in infection control and Staphylococcus aureus decolonization. Antimicrob. Agents Chemother. 64(9), e00682-20 (2020).

15. 3M Health Care. Facts about iodine and iodophors. https://multimedia.3m.com/mws/media/716284O/3m-skin-and-nasal-antiseptic-facts-about-iodine-and-iodophors.pdf

16. Frank S, Brown SM, Capriotti JA, Westover JB, Pelletier JS, Tessema B. In vitro efficacy of a povidone-iodine nasal antiseptic for rapid inactivation of SARS-CoV-2. JAMA Otolaryngol. Head Neck Surg. 146(11), 1-5 (2020).

17. Kratzel A, Todt D, V'kovski P et al. Inactivation of severe acute respiratory syndrome coronavirus 2 by WHO-recommended hand rub formulations and alcohols. Emerg. Infect. Dis. 26(7), 1592-1595 (2020).

18. Meister TL, Brüggemann Y, Todt D et al. Virucidal efficacy of different oral rinses against SARS-CoV-2. J. Infect. Dis. 222(8), 1289-1292 (2020).

-• This in vitro study compares the efficacy of Listerine, PVP-I and hydrogen peroxide against SARS-CoV-2. 
19. Bansal S, Jonsson CB, Taylor SL et al. Iota-carrageenan and Xylitol inhibit SARS-CoV-2 in cell culture. bioRxiv doi:10.1101/2020.08.19.225854 (2020) (Epub ahead of print).

- Demonstrates the ability of iota-carrageenan with xylitol to inhibit the SARS-CoV-2 virus.

20. Aga Khan University. A clinical trial of gargling agents in reducing intraoral viral load among COVID-19 patients. https://ClinicalTrials.gov/show/NCT04341688

21. Kim JH, Rimmer J, Mrad N, Ahmadzada S, Harvey RJ. Betadine has a ciliotoxic effect on ciliated human respiratory cells. J. Laryngol. Otol. 129(Suppl. 1), S45-S50 (2015).

22. Reimer K, Wichelhaus TA, Schäfer V et al. Antimicrobial effectiveness of povidone-iodine and consequences for new application areas. Dermatology 204(Suppl. 1), 114-120 (2002).

23. Burton MJ, Clarkson JE, Goulao B et al. Antimicrobial mouthwashes (gargling) and nasal sprays administered to patients with suspected or confirmed COVID-19 infection to improve patient outcomes and to protect healthcare workers treating them. Cochrane Database Syst. Rev. 9, Cd013627 (2020).

24. Mitsui T, Harasawa R. The effects of essential oil, povidone-iodine, and chlorhexidine mouthwash on salivary nitrate/nitrite and nitrate-reducing bacteria. J. Oral Sci. 59(4), 597-601 (2017).

25. Leibbrandt A, Meier C, König-Schuster M et al. Iota-carrageenan is a potent inhibitor of influenza A virus infection. PLoS ONE 5(12), e14320 (2010).

26. Harden EA, Falshaw R, Carnachan SM, Kern ER, Prichard MN. Virucidal activity of polysaccharide extracts from four algal species against herpes simplex virus. Antivir. Res. 83(3), 282-289 (2009).

27. Eccles R, Meier C, Jawad M, Weinmüllner R, Grassauer A, Prieschl-Grassauer E. Efficacy and safety of an antiviral iota-carrageenan nasal spray: a randomized, double-blind, placebo-controlled exploratory study in volunteers with early symptoms of the common cold. Respir. Res. 11(1), 108 (2010).

28. Cheudjeu A. Correlation of D-xylose with severity and morbidity-related factors of COVID-19 and possible therapeutic use of D-xylose and antibiotics for COVID-19. Life Sci. 260, 118335 (2020).

29. Singh S, Sharma N, Singh U, Singh T, Mangal DK, Singh V. Nasopharyngeal wash in preventing and treating upper respiratory tract infections: could it prevent COVID-19? Lung India 37(3), 246-251 (2020).

30. Ramalingam S, Graham C, Dove J, Morrice L, Sheikh A. A pilot, open labelled, randomised controlled trial of hypertonic saline nasal irrigation and gargling for the common cold. Sci. Rep. 9(1), 1-11 (2019).

- Demonstrates the efficacy of hypertonic saline nasal irrigation and gargling in reducing symptoms of the common cold.

31. Ramalingam S, Graham C, Dove J, Morrice L, Sheikh A. Hypertonic saline nasal irrigation and gargling should be considered as a treatment option for COVID-19. J. Glob. Health 10(1), 010332 (2020).

32. Ramalingam S, Cai B, Wong J et al. Antiviral innate immune response in non-myeloid cells is augmented by chloride ions via an increase in intracellular hypochlorous acid levels. Sci. Rep. 8(1), 13630 (2018).

33. Machado RRG, Glaser T, Araujo DB et al. Hypertonic saline solution inhibits SARS-CoV-2 in vitro assay. bioRxiv doi:10.1101/2020.08.04.235549 (2020) (Epub ahead of print).

- This in vitro study demonstrates the efficacy of hypertonic saline solution in inhibiting SARS-CoV-2.

34. Tarran R, Grubb BR, Gatzy JT, Davis CW, Boucher RC. The relative roles of passive surface forces and active ion transport in the modulation of airway surface liquid volume and composition. J. Gen. Physiol. 118(2), 223-236 (2001).

35. Knowles MR, Robinson JM, Wood RE et al. Ion composition of airway surface liquid of patients with cystic fibrosis as compared with normal and disease-control subjects. J. Clin. Invest. 100(10), 2588-2595 (1997).

36. Rabenau HF, Cinatl J, Morgenstern B, Bauer G, Preiser W, Doerr HW. Stability and inactivation of SARS coronavirus. Med. Microbiol. Immunol. 194(1-2), 1-6 (2005).

37. Asif M, Saleem M, Saadullah M, Yaseen HS, Al Zarzour R. COVID-19 and therapy with essential oils having antiviral, anti-inflammatory, and immunomodulatory properties. Inflammopharmacology 28(5), 1153-1161 (2020).

38. Steed LL, Costello J, Lohia S, Jones T, Spannhake EW, Nguyen S. Reduction of nasal Staphylococcus aureus carriage in health care professionals by treatment with a nonantibiotic, alcohol-based nasal antiseptic. Am. J. Infect. Control 42(8), 841-846 (2014).

39. Bernstein D, Schiff G, Echler G, Prince A, Feller M, Briner W. In vitro virucidal effectiveness of a $0.12 \%$-chlorhexidine gluconate mouthrinse. J. Dent. Res. 69(3), 874-876 (1990).

40. Brecx M, Netuschil L, Reichert B, Schreil G. Efficacy of Listerine, meridol and chlorhexidine mouthrinses on plaque, gingivitis and plaque bacteria vitality. J. Clin. Periodontol. 17(5), 292-297 (1990).

41. Hidalgo E, Dominguez C. Mechanisms underlying chlorhexidine-induced cytotoxicity. Toxicol. In Vitro 15(4-5), 271-276 (2001).

42. Kampf G, Todt D, Pfaender S, Steinmann E. Persistence of coronaviruses on inanimate surfaces and their inactivation with biocidal agents. J. Hosp. Infect. 104(3), 246-251 (2020).

43. Huang SS. Chlorhexidine-based decolonization to reduce healthcare-associated infections and multidrug-resistant organisms (MDROs): who, what, where, when, and why? J. Hosp. Infect. 103(3), 235-243 (2019). 
44. Yoon JG, Yoon J, Song JY et al. Clinical significance of a high SARS-CoV-2 viral load in the saliva. J. Korean Med. Sci. 35(20), e195 (2020).

45. Segers P, Speekenbrink RGH, Ubbink DT, Van Ogtrop ML, De Mol BA. Prevention of nosocomial infection in cardiac surgery by decontamination of the nasopharynx and oropharynx with chlorhexidine gluconate a randomized controlled trial. JAMA 296(20), 2460-2466 (2006).

46. Omidbakhsh N, Sattar SA. Broad-spectrum microbicidal activity, toxicologic assessment, and materials compatibility of a new generation of accelerated hydrogen peroxide-based environmental surface disinfectant. Am. J. Infect. Control 34(5), 251-257 (2006).

47. Nobahar M, Razavi MR, Malek F, Ghorbani R. Effects of hydrogen peroxide mouthwash on preventing ventilator-associated pneumonia in patients admitted to the intensive care unit. Braz. J. Infect. Dis. 20(5), 444-450 (2016).

48. Gottsauner MJ, Michaelides I, Schmidt B et al. A prospective clinical pilot study on the effects of a hydrogen peroxide mouthrinse on the intraoral viral load of SARS-CoV-2. Clin. Oral. Investig. 24(10), 3707-3713 (2020).

49. Poitiers University Hospital. Povidone iodine mouthwash, gargle, and nasal spray to reduce naso-pharyngeal viral load in patients with COVID-19. https://ClinicalTrials.gov/show/NCT04371965

50. Stanford University. PVP-I nasal sprays and SARS-CoV-2 nasopharyngeal titers (for COVID-19). https://ClinicalTrials.gov/show/NCT04347954

51. Povidone-iodine vs essential oil vs tap water gargling for COVID-19 patients. https://ClinicalTrials.gov/show/NCT04410159 Universiti Sains Islam Malaysia

52. Efficacy of a nasal spray containing iota-carrageenan in the prophylaxis of COVID-19 disease in health personnel dedicated to patients care with COVID-19 disease. https://ClinicalTrials.gov/show/NCT04521322 Centro de Educación Medica e Investigaciones Clínicas Norberto Quirno

53. University of Kentucky. COVID-19: povidone-iodine intranasal prophylaxis in front-line healthcare personnel and inpatients. https://ClinicalTrials.gov/show/NCT04364802

54. Claude Bernard University. COVID-19: nasal and salivary detection of the SARS-CoV-2 virus after antiviral mouthrinses. https://ClinicalTrials.gov/show/NCT04352959

55. St. Paul's Hospital, Canada. Povidone-iodine rinses in the management of COVID-19. https://ClinicalTrials.gov/show/NCT04449965

56. Gargling and nasal rinses to reduce oro- and nasopharyngeal viral load in patients with COVID-19. https://ClinicalTrials.gov/show/NCT04344236 NYU Langone Health

57. University of California, San Francisco. Antiseptic mouthwash pre-procedural rinse on SARS-CoV-2 load (COVID-19). https://ClinicalTrials.gov/show/NCT04409873

58. SHIELD study: using naso-oropharyngeal antiseptic decolonization to reduce COVID-19 viral shedding. https://ClinicalTrials.gov/show/NCT04478019 University of Wisconsin, Madison

59. Pi Research Consultancy Center, Bangladesh. Virucidal effect of povidone iodine on COVID-19 in-vivo. https://ClinicalTrials.gov/show/NCT04549376

60. Hampshire Hospitals NHS Foundation Trust. SINUS WASH pilot study in adults testing positive for COVID-19. https://ClinicalTrials.gov/show/NCT04393792

61. Dentaid SL. Pilot study to evaluate effect of CHX0.12/CPC 0.05 of SARS-CoV-2 viral load in COVID-19 patients. https://ClinicalTrials.gov/show/NCT04563689

62. Sanotize Research and Development corp. Nitric oxide releasing solutions to prevent and treat mild/moderate COVID-19 infection. https://ClinicalTrials.gov/show/NCT04337918

63. Evaluation of the load of SARS-CoV-2 virus in oral cavity, oropharinge and saliva of patients with COVID-19 after disinfection with oral antimicrobial solutions: a pilot study. https://ClinicalTrials.gov/show/NCT04537962 Hospital Israelita Albert Einstein

64. Sanotize Research and Development corp. Nitric oxide releasing solution to treat and prevent exacerbation of mild COVID-19 infection. https://ClinicalTrials.gov/show/NCT04443868

65. Vanderbilt University Medical Center. Impact of nasal saline irrigations on viral load in patients with COVID-19. https://ClinicalTrials.gov/show/NCT04347538

66. Kimura KS, Freeman MH, Wessinger BC et al. Interim analysis of an open-label randomized controlled trial evaluating nasal irrigations in non-hospitalized patients with coronavirus disease 2019. Int. Forum Allergy Rhinol. 10(12), 1325-1328 (2020).

67. University of Edinburgh. Hypertonic saline nasal irrigation and gargling in suspected or confirmed COVID-19 (ELVIS COVID-19). https://ClinicalTrials.gov/show/NCT04382131

68. Kirk-Bayley J, Challacombe S, Sunkaraneni S, Combes J. The use of povidone iodine nasal spray and mouthwash during the current COVID-19 pandemic may protect healthcare workers and reduce cross infection. Available at SSRN 3563092 (2020). https://papers.ssrn.com/sol3/papers.cfm?

69. Challacombe SJ, Kirk-Bayley J, Sunkaraneni VS, Combes J. Povidone iodine. Br. Dent. J. 228(9), 656-657 (2020).

70. Principi N, Esposito S. Nasal irrigation: an imprecisely defined medical procedure. Int. J. Environ. Res. Public Health 14(5), 516 (2017). 
71. Statkute E, Rubina A, O'donnell VB, Thomas DW, Stanton RJ. Brief report: the virucidal efficacy of oral rinse components against SARS-CoV-2 in vitro. bioRxiv doi:10.1101/2020.11.13.381079 (2020) (Epub ahead of print).

72. Khokhar M, Roy D, Purohit P, Goyal M, Setia P. Viricidal treatments for prevention of coronavirus infection. Pathog. Glob. Health 114(7), 349-359 (2020).

73. James P, Worthington HV, Parnell C et al. Chlorhexidine mouthrinse as an adjunctive treatment for gingival health. Cochrane Database Syst. Rev. 3(3), Cd008676 (2017).

74. Carey CM. Tooth whitening: what we now know. J. Evid. Based Dent. Pract. 14(Suppl.), 70-76 (2014).

75. Hebar A, Koller C, Seifert JM et al. Non-clinical safety evaluation of intranasal iota-carrageenan. PLoS ONE 10(4), e0122911 (2015).

76. Eccles R, Winther B, Johnston SL, Robinson P, Trampisch M, Koelsch S. Efficacy and safety of iota-carrageenan nasal spray versus placebo in early treatment of the common cold in adults: the ICICC trial. Respir. Res. 16, 121 (2015).

77. Koenighofer M, Lion T, Bodenteich A et al. Carrageenan nasal spray in virus confirmed common cold: individual patient data analysis of two randomized controlled trials. Multidiscip. Respir. Med. 9(1), 57 (2014).

- This analysis of two randomized controlled trials demonstrates the potential efficacy of carrageenan nasal spray against the common cold.

78. NHS Lothian. Hypertonic saline nasal irrigation and gargling for the common cold. https://ClinicalTrials.gov/show/NCT02438579

79. Boehringer Ingelheim. Iota-carrageenan nasal spray in common cold. https://ClinicalTrials.gov/show/NCT01944631

80. Fazekas T, Eickhoff P, Pruckner N et al. Lessons learned from a double-blind randomised placebo-controlled study with a iota-carrageenan nasal spray as medical device in children with acute symptoms of common cold. BMC Complement. Altern. Med. 12, 147 (2012).

81. Ludwig M, Enzenhofer E, Schneider S et al. Efficacy of a carrageenan nasal spray in patients with common cold: a randomized controlled trial. Respir. Res. 14(1), 124 (2013).

82. Almas K. The antimicrobial effects of extracts of Azadirachta indica (Neem) and Salvadora persica (Arak) chewing sticks. Indian J. Dent. Res. 10(1), 23-26 (1999).

83. Subapriya R, Nagini S. Medicinal properties of neem leaves: a review. Curr. Med. Chem. Anticancer Agents. 5(2), $149-146$ (2005).

84. Braga SS. Cyclodextrins: emerging medicines of the new millennium. Biomolecules 9(12), 801 (2019).

85. Stefano GB, Esch T, Kream RM. Potential immunoregulatory and antiviral/SARS-CoV-2 activities of nitric oxide. Med. Sci. Monit. 26, e925679 (2020).

86. Hippensteel JA, Lariviere WB, Colbert JF, Langouët-Astrié CJ, Schmidt EP. Heparin as a therapy for COVID-19: current evidence and future possibilities. Am. J. Physiol. Lung Cell Mol. Physiol. 319(2), L211-1217 (2020).

87. Meyers C, Robison R, Milici J et al. Lowering the transmission and spread of human coronavirus. J. Med. Virol. doi:10.1002/jmv.26514 (2020) (Epub ahead of print).

88. Rosen PL, Palmer JN, O’malley BW Jr, Cohen NA. Surfactants in the management of rhinopathologies. Am. J. Rhinol. Allergy 27(3), 177-180 (2013). 